\title{
A Contrastive Analysis of the Agreement System of Ogba and English Languages
}

\author{
Dr. Enwere, K.I.*, Nwagwu, Blessing \\ Department of English and Communication Art, Ignatius Ajuru University of Education Rumuolumeni, Port \\ Harcourt.
}

*Corresponding Author: Dr. Enwere, K.I., Department of English and Communication Art, Ignatius Ajuru University of Education Rumuolumeni, Port Harcourt, Nigeria

\begin{abstract}
This paper focused on the agreement system of Ogba and English verb phrases using a contrastive analysis, with a view to analyze, compare and contrast the agreement system of Ogba and English languages. The data collected randomly comprises the researchers' knowledge as L1 users and L2 user of English and also from books and other library materials that are available in both languages. The data collection technique that was used in this study is the unstructured oral interview. An analysis of the data revealed that both languages are of distinct background, the focus of this paper exist in both languages, where English language is agreement rich, Ogba language is not. It is therefore concluded that there exist differences and similarities in the agreement system of the Ogba and English languages.
\end{abstract}

Key Words: Ogba, English Language, contrastive analysis.

\section{INTRODUCTION}

Language scholars (linguists) believe that the endowment for the creation of language is innate and divine, available only to humans. To them, it is with language that man dominates and rules his world, even at the expense of his closest relatives in the animal kingdom. This implies that every normal human being must speak at least one human language, (Ndimele 2014).

Furthermore, every natural language has what Ndimele calls Universal Grammar (UG) which lays down the basic principles for each language also called the core grammar to select the parameters along which the principles are realized, (Ndimele 2014). Thus, an important part of language study must include the parameters or rules that govern the combination of sounds to form morpheme, words, phrases, clauses, and sentences.

Yul-Ifode (2001), affirms that there is no language without grammar (that is, innate linguistic rules that reside in the mind of competent speakers of a language). Language is the human essence, the distinctive qualities of mind that are unique to man, the quintessence of man (Ejele, 1996). This in essence means that the difference between man and animal is the way language is expressed, the ability of using language clearly differentiates man from other animals. The use of language is what makes human beings higher than other animals. Through language, human beings derive life and power; and as human beings, we use language to develop our environment, learn and even teach other languages. To know a language is to be competent in the rules of such a language and use it effectively such that others that know the same language will understand and discuss with you without stress.

Hence, in Adeyemi, O.B. (1996, p.1), "Language is a system of conventional signs used to serve the primary purpose of conveying meaning". Adeyemi's definition of language seems to be more elaborate. It tries by a certain society, because the main reason for language is to pass information, ideas, feelings to one another. All the notions about language have to do with one knowing a particular language, and being able to communicate by using it. For the fact that human beings live in communities or societies known as social groups, communication with one another is necessary for the necessary for the successful and meaningful co-existence of the individual. When human beings communicate with one another, they express feelings, ideas and desires, this method of communicating ideas and feeling by human beings is done by means of a system of sound symbols. Ogum (2017, p.2), made a useful contribution to the use of language. 
Chomsky (1972) further explained that "When we study human language, we are approaching what might call "human essence" the distinctive quality of mind that are, so far as we know, unique to man." Therefore, the ability of man to possess language, more than any attribute, distinguishes man from other animals.

Language is also said to be "a complex, orderly structure (whose) complex, orderly structure (whose) complexity shows in the richness of what can be expressed in it, and its orderliness in the fact that everyone can produce brand-new sentences which others immediately understand, a feat which is miraculous, unless we all have at command some general rules or principles which govern our language". It is obvious in that definition that language is governed by rules and structure dependent.

Allerton (1979:18-21) defines language as 'the fully developed natural human communication systems based on speech', where "communication involves sending ideas or information from person to person". The information so transmitted is called 'message' and the speech sounds themselves are called arbitrary signals consisting of one type of medium or channel encoding the information being sent.

The speech sounds are used are arbitrarily (or without reason) patterned to carry meaning. By patterning, we mean that a language, using limited set of speech sounds, contains a definite number of rules, specifying the sequential order of producing these sounds for them, to convey desired information to the recipient.

Allerton's definition mentions the sound bases of language and its main function as a tool for information transfer, in addition to introducing a few other properties of natural human languages.

According to Williamson (1984:1), "Language is the chief means by which human beings communicate. It is found in two main forms, spoken and written. Of these, spoken language is more important." In her view, the spoken language is more natural and more basic than the written language.

So far, number of facts as we have outlined emerge from these definitions, however, what we want to know at this level (Introduction to language) about the definition of language is whether all natural human languages have something in common not shared by other systems of communication that is non-human. This is line with Chomsky's (1972) definition as mentioned in our discussions, where he affirms that man's capacity to acquire language, more than any other characteristics, distinguishes man from other animals.

Consequently, Ogba and English competent speakers are able to acquire or learn the languages as a result of the rules that govern them. Language is used around every human. It is important for the existence of man, yet many people encounter difficulty in learning a second language. Language is seen by scholars as a medium of communication and interaction among human beings.

\subsection{Linguistic Situation of Ogba}

Ogba is an igboid (related to Igbo) language which belong to the Benue-Congo family of the NigerCongo phylum just like some other languages of Rivers State: Ekpeye, Ikwere and Echie. It is spoken in part of Ogba/Egbema/Ndoni Local Government Area of Rivers State.

Ogba language is said to have three dialects: Egni, Igburu, and Usomini. The degree of the relatedness of these dialects have not been adequately established, thus, the classification for now is said to be merely impressionistic, (Isaac 2018).

\subsection{Conceptual Review of the Verb}

According to Nwala (2016), the verb is traditionally defined as a doing or action word. In his words, descriptively, verbs are message carriers. They determine when expressions make meaning and when they do not. As a message carrier, the verb coordinates and links all the other elements in the clause. It links the subjects and the objects and shows their array of relationships. (p.45).

A hypothetical tree diagram which explicates the function of verbs in clause: 


\section{Sentence}

Subject Verb

Object

Nwala (2016: p.46)

(From the above diagram, it is clear that the verb is at the center of sentence formation).

Ndimele (1993: p.92) defines verb as "a word that can change its form to reflect tense, aspect, voice, mood, person, number, and which can occur as the only element in a minimal predicate of a sentence". The verb is typically the most important words in the predicate area of a sentence. According to him, the predicator is that part of a sentence which says something about the subject. The most typical verbs express actions or states. He further adds that a verb is "the key word in a predicate slot of a sentence". He classified verbs using three criteria: syntactic, semantic and morphological behaviours. On their part, Baridisi (1995: p.23) and Crystal (1997: p.410) agree with Ndimele in his semantic definition of the verb. In Baridisi's word, "the verb is that part of speech that expresses an action, process or a state of being". Crystal (1997: p.410), observes that a verb is an "element which singly or in combination with other verbs is used as minimal predicate of a sentence, co-occurring with a subject". According to Crystal, the verb is said to be the nucleus or the head of the VP. Furthermore, Tallerman (1998: p.35) asserts that in all languages of the world, the verb falls into three sub-classes namely: transitive, intransitive and ditransitive. According to him, "the most common function of verbs is as predicates: these denotes situations, events, actions, processes and so on". Ken-Maduako (2004: p.95) emphasizes that a verb is a word which says something about the subject; its state of being and feelings.

She adds that a verb also states "what the subject has done and what was done to and for the object". To her, the verb can be divided into two

sub-classes: Transitive and Intransitive verbs. In her opinion, a transitive verb is one which describes an action which is passed on from the subject to the object. Thus every verb which can take an object is referred to as a transitive verb where the action is passed from a doer (the subject) to a receiver (the direct object): (P.112).

$\begin{array}{lcc}\text { Tonye } & \text { read } & \text { her book } \\ \downarrow & \downarrow & \downarrow \\ \text { Subject } & \text { verb } & \text { direct object } \\ \text { Bisi } & \text { slapped } & \text { her friend } \\ \downarrow & \downarrow & \downarrow \\ \text { Subject } & \text { verb } & \text { direct object }\end{array}$

The intransitive verb on the other hand, is the verb that does not require an object to complete its meaning:

$\begin{array}{lcc}\text { Bisi } & \text { slept } & \text { soundly } \\ \downarrow & \downarrow & \downarrow \\ \text { Subject } & \text { verb } & \text { complement } \\ \text { James } & \text { is } & \text { a banker } \\ \downarrow & \downarrow & \downarrow \\ \text { Subject } & \text { verb } & \text { complement }\end{array}$

Nwala (2016: P.53), agrees with Ken-Maduako (2004: p.112), that transitive verbs are the type of verbs that takes direct object in sentences. He notes that, when the action of the subject is transferred to the object of the sentence through the function of the verb, we describe such a verb as transitive: 
The man killed the dog

The teacher flogged the student.

Transitive verbs make possible the formation of passive sentences, that is, a situation where the attention is shifted from the subject of the sentence to the object of the sentence:

The dog was killed by the man.

The student was flogged by the teacher.

We cannot say to a large extent whether a verb is transitive or not except when the verb is used in a sentence. This is so because a verb can be transitive in one sentence and intransitive in another. The intransitive verbs are direct opposites of the transitive verbs.

They do not take direct objects in sentences:

He runs admiringly.

She plays fantastically.

He eats every day.

According to Nwala (2016: p.55), the case of mono- and di-transitive verbs are also important when discussing verbs.

Mono- means one, while di- means two.

A mono-transitive verb therefore takes one subject in a sentence, e.g.,

Jane cut the stick.

A di-transitive verb is one that takes two objects;

Jane gave the children bread.

Glory bought Mary a present.

Also Kari (2004: p.35) affirms that verbs serve as the head of VPs and can be modified by an adverb or an adverbial. In the opinion of Kari, a verb can occur as the only word in the predicate part of a sentence. Similarly, Kari (2015: p.125) contends that:

Like nouns, verbs are also among the word categories that are present in all languages of the world. In all languages, something has to be said about something. The element in a sentence... that says something is the verb. Verbs have grammatical features such as tense, aspect, mood, person, number and negation associated with them.

From the foregoing assertions, it is clear that the term "verb" is language universal. This implies that there is no language without the verb.

\section{THE PHRASE}

Tomori (1977: p.65) affirms that a phrase is a group of words or a single word that has the possibility of operating as a functional constituent in a sentence structure. Ndimele (1992; 1999: p.90), KenMaduako (2004: p.191), and Worukwo (2002: p.28) collectively agree with Tomori that a phrase is a group of words or single word. Ndimele observes that generally, a phrase (which he also referred to as a maximal projection) must have a head word that determines the nature of the overall phrase. Ndimele (1999: p 90) simply defines a phrase as "a group of words which are joined together following the rules of the grammar of a language" under investigation. According to him, sentences are not only built out of words belonging to various word-level category but also out of phrases belonging to a corresponding set of phrasal categories.

More so, Ndimele states that phrases in language are internally structured following a particular pattern, and based on the grammatical rules that governs such language. He emphasizes that the notion of head is very important in the discussion of phrases. He further adds that the head of a phrase is the most important part of that structure (construction). The other linguistic element which may occur before or after it (the head of a phrase) are optional elements which modify the head. Phrase is one of the terms in linguistics that has received many definitions. Most of the early and traditional 
definitions are hinges around complete sense. That is to say that a phrase was looked at as that which does not make a complete sense. We do not want to go into this type of reasoning but suffice it to say that the definition of phrase as that which does not make a complete sense has long been dropped. The reason for the abandonment is that such a definition is prescriptive and secondly, because of the ambiguous nature of the term complete sense.

Put descriptively, a phrase is a word or group of words, which lack some basic sentence parts. It is a group of related words which is grammatically equivalent to a single word and which does not have its own subject and predicate. In recent description phrase, the notion of headedness is necessary. Every phrase has a head which defines its grammatical membership. The head of a phrase gives the phrase its essential character, (Ndimele, 1992).

\section{The Verb Phrase In English}

Ahaotu (2011: p.35) and Lamidi (2008: p.40) claim that a verb phrase is a group of word that is headed by the verb. Lamidi (2008: p.40) states that every VP usually has lexical verbs as the head. According to him, the lexical verb that functions as the head is determined by the type of verb that exist in the constituent. He used a single rule to represent all the possibilities for rewriting a VP thus:

$$
\mathrm{VP} \rightarrow\{\mathrm{V}+(\mathrm{NP})+(\mathrm{ADVP})+(\mathrm{PP})\}
$$

Where $\mathrm{V}$ is the verb that serves as the head and the obligatory element in the VP, NP stands for noun phrase that occurs in the object position, ADVP is an adverbial and PP refers to a prepositional phrase. All the element of the VP occurs in the predicate part of a sentence. From the rule of writing the VP as presented by Lamidi (2008: p.42), it is deduced that the constituents of VP in English are:

a) A VP can comprise a single verb $(\mathrm{VP} \rightarrow \mathrm{V})$

b) It can also consist of an obligatory verb and an optional NP (VP $\rightarrow \mathrm{V}+\mathrm{NP})$

c) A VP can consist of an obligatory verb, NP and ADVP $(\mathrm{VP} \rightarrow \mathrm{V}+\mathrm{NP}+\mathrm{ADVP})$

d) A VP can comprise a V, NP, ADVP and PP (VP $\rightarrow \mathrm{V}+\mathrm{NP}+\mathrm{ADVP}+\mathrm{PP})$

Ahaotu (2011: p.36) asserts that a VP consists of a lexical verb and its auxiliaries. He notes that a VP occupies a verb position in a sentence and indicates the action of the subject or its condition. Furthermore, he states that VPs function in two ways: as indicator of action of the subject and as indicator of the state (condition) of the subject.

\section{The Verb Phrase In OGba}

This is a group of grammatical words in Ogba where verbs act as the head. Like the English language, the Ogba verb phrase always govern the predicate and assigns functions to the complements. Below is a common structure of the Ogba verb phrase:

1. Adammariiri

[Adamma PST food]

Adamma ate food

2. Precious bajenzukor

[Precious FUT go church]

Precious will go to church

3. Ngoziyabasaeferenye

[Ngozi FUT wash plate the]

Ngozi will wash the plate

As seen in the above sentences, Ogba is an SVO language. The verb is the head of the verb phrase or predicate and has an object which functions as the complement.

\section{ANALYSIS/DISCUSSION}

\section{Verb Agreement (Number)}




\begin{tabular}{|c|c|c|}
\hline $\mathbf{S} / \mathbf{N}$ & English & Ogba \\
\hline $1 \mathrm{a}$ & This clothistoo small for me & Aworagbakahiranimnkor \\
\hline $1 \mathrm{~b}$ & These clothesare too small for me & Aworndorkahiranimnkor \\
\hline $2 \mathrm{a}$ & This vegetableis not green & Ekwo-ohiagbakawuuwu \\
\hline $2 b$ & These vegetablesare not green & Ekwo-ohindorkawuuwu \\
\hline $3 \mathrm{a}$ & The manwas here & Nwokonyebiameedor \\
\hline $3 \mathrm{~b}$ & These menwere here & Nwokondorbiameedor \\
\hline $4 \mathrm{a}$ & Shewrites everyday & Ogbagaheeosubochi \\
\hline $4 \mathrm{~b}$ & Theywrite everyday & worgbagaheeosubochi \\
\hline $5 \mathrm{a}$ & This boyis not behaving well & Ikenwaagbaka di kpaagwuaoka \\
\hline $5 b$ & Those boysare not behaving well & Ikenwandeeka di kpaagwuaoka \\
\hline $6 a$ & The birdflies over the house & Nnunuelunyewhebiwheulonye \\
\hline $6 \mathrm{~b}$ & The birdsfly over the house & Nnunuelundeenyewhebiwheulonye \\
\hline $7 \mathrm{a}$ & The employeeis enjoying the new building & Onye-orunyedionwuriyaulouhurunye \\
\hline $7 \mathrm{~b}$ & The employeesare enjoying the new building & Nde-orundeedionwuriyaulouhurunye \\
\hline $8 \mathrm{a}$ & Heis going to work & Odijirerioru \\
\hline $8 \mathrm{~b}$ & Theyare going to work & Wordijirerioru \\
\hline $9 \mathrm{a}$ & The dog always barks at the driver & Nkitanyebaniganwokoaniynagaugboraliambna \\
\hline $9 \mathrm{~b}$ & The dogs always bark at the driver & Nkitandeenyebaniganwokoaniynagaugboraliambna \\
\hline $10 \mathrm{a}$ & The childis crying & Nwanyedikwnaekwa \\
\hline $10 \mathrm{~b}$ & The childrenare crying & Umundeenyedikwnaekwa \\
\hline
\end{tabular}

Agreement

Linguistically speaking, agreement is a term that shows the number relationship between the subject and the verb in a sentence, in that, if the subject is singular, the verb must be singular and if the subject is plural, the verb must be plural. Agreement describes languages that are favoured in the subject verb relationship and those that are not. In English, as table 14 clearly show the subject verb agreement is morphologically and lexically marked.

1a. this cloth is too small for me

1b. these clothes are too small for me

2a. she writes everyday

2 b. they write everyday

3a. the bird flies over the house

3 b. the birds fly over the house

4a. the dog always barks at the driver

4b. the dogs always bark at the driver

5a. the employee is enjoying the new building

5b. the employees are enjoying the new building

Ogba language is not an agreement rich language. Agreement of subjects and verbs are abstract (existing in thought or as idea) but does not have a physical reality. It forms part of the competence of a fluent native speaker. This to say is one of the noticeable differences between the Ogba and the English language verbs. As will be shown in the examples below in Ogba, the verb does not change its form to show any difference in number. It remains the same for both singular and plural subjects. Sententially, the numbers of Ogba subjects are revealed in the idea conveyed in the sentence.

Awondorkahiranimnkor

These clothesare too small for me

Awoagbakahiranimnkor

This clothis too small for Chinonye

Ogbagaheeosubochi

Shewrites everyday 
Worgbagaheeosubochi

Theywrite everyday

Ikewnaagbaka di kpaagwuaoka

This boyis not behaving well

Ikewandeeka di kpaagwuaoka

Those boysare not behaving well

From the above examples, the ka and gbaga in Ogba did not change their forms to show any difference in number.

\section{CONClusion/Summary}

Every language is unique and linguistically complete. The foregoing reaffirms the assertion that there exist differences and similarities in the agreement system of Ogba and the English verb phrases

Thus, the concept that has been investigated and its findings stand to serve as an eye opener to scholars, students and language users at large. The researchers therefore firmly and strongly believe that this work in clear terms has shown that human languages are linguistically unique and a priceless gift from God, because the research has shown that two languages of distinct background can appear to have some similarities and dissimilarities

\section{RECOMMENDATIONS}

To enhance the study of English as a second language for the fluent native speakers of Ogba language, the researcher recommends the following:

1. The orthography of Ogba language should be further developed together with the English orthography to aid the second language learner

2. Adult education should be aided and made more practical, especially in our villages since adults are more conversant with indigenous languages.

3. A detailed contrastive and comparative investigation into such areas as; tense system and verb complementation of both languages should be carried out as it will be very beneficial to the Ogba second language learner of the English language.

\section{REFERENCES}

[1] Aaron, N.O. (1995). Echie verb phrase. Unpublished M.A. Thesis, University of Port Harcourt.

[2] Adeyemi, O.B. (1996). Introduction to english grammar and writing skills. Encrownfiit Publisher.

[3] Allerton, D.J. (1979). Essentials of grammatical theory. Routledge \& Kegan Paul.

[4] Anyadiegwu, A. (2007). Principles and methods of teaching english as a second language. Ausichaki int'l Publishers.

[5] Benamaisia, O. (2001). The Ibani verb phrase. Unpublished M.A. Thesis. University of Port Harcourt.

[6] Corder, S. P. (1967). "The significance of learner's errors": International review of applied, Linguistics. Oxford University Press.

[7] Crystal, D. (1977). A dictionary of linguistics and phonetics. Oxford University Press.

[8] Headbloom, A. G. (1979). Error analysis and theoretical considerations in second language Learning. In E. Ubahakwe (Ed.), The teaching of English studies reading for colleges Universities. Ibadan University Press.

[9] Ihiejirika, W.C. \& Christie O. (2011). Research methods in linguistics and communication studies. University of Port Harcourt Press Ltd.

[10] Isaac, C. (2007). Oral antecedents to African drama: A case study of Ogba traditional festival (EgwuOgba). Unpublished B. ED Long essay, Rivers State College of Education.

[11] ......... (2018). An analysis of Ogba noun phrase. Unpublished M.A. dissertation. University of Port Harcourt.

[12] Ken-Maduako, I. (2004). English grammar and usage. Edik Integrated Services.

[13] Lado, R. (1968). Linguistics across cultures: Applied linguistics for language teachers. Michigan University Press. 
[14] Ndimele, O.-M. (1992). Principles and parameters of universal grammar: A government Binding approach. African Educational Services.

[15] ......... (1993). An advanced english grammar and usage. National Institute for Nigerian Languages.

[16] ......... (1999). Morphology and syntax. M\&J Grand Orbit.

[17] .......... (2003). A concise grammar and lexicon of Echie. National Institute for Nigerian Languages.

[18] ......... (2014). Nigerian core grammars in global communication: Any glimmer of hope in this looming Armageddon? An inaugural lecture. Series: 112. University of Port Harcourt Press.

[19] Nwala, M.A. (2015). Introduction to linguistics: A First Course. Revised Edition. Obisco Nig. Enterprises.

[20] ......... (2016). Introduction to syntax: the student's guide. Wisdom Press Limited.

[21] Obi-Okoye, A. F. (2008). An introduction to applied English linguistics: From theory to practice. Frefabag Investment Limited.

[22] Ogum, D. N. \&Etim, R. E. (2013). Essentials of communication in english. Eddy-Joe Publishers.

[23] Ohia, B. \&Onyedibia, H.O. (2003). The Ogba nation 1460-2003. Charles SWORH Nigeria.

[24] Worukwo, G. (2002). An outline of english grammar. Celwil Nigeria Ltd.

[25] .......... (2004). Transformational and generative english grammar. Celwil Nigeria.

[26] Wale, A. (2012). Use of english, a manual on communicative skills for tertiary institutions, Ile-Ife: Department of English, ObafemiAwolowo University Press.

[27] Yul-Ifode, S. (2001). An introduction to language in history and society. University of Port Harcourt.

Citation: Dr. Enwere, K.I., Nwagwu, Blessing. "A Contrastive Analysis of the Agreement System of Ogba and English Languages" International Journal of Humanities Social Sciences and Education (IJHSSE), vol 8, no. 7, 2021, pp. 59-66 doi: https://doi.org/10.20431/2349-0381.0807007.

Copyright: (C) 2021 Authors. This is an open-access article distributed under the terms of the Creative Commons Attribution License, which permits unrestricted use, distribution, and reproduction in any medium, provided the original author and source are credited. 